\title{
Improving the efficiency of gas exchange during alimentary biocorrection of the nutritional status of students and teachers of an engineering university
}

\author{
Natalya Rodionova ${ }^{1 *}$, Michael Syromyatnikov ${ }^{1}$, Evgeny Popov $^{1}$, Ekaterina Pozhidaeva ${ }^{1}$, Natalya Pastukhova $^{1}$, and \\ Alexander Rodionov ${ }^{1}$ \\ ${ }^{1}$ Department of service and restaurant business Voronezh State University of Engineering Technologies, Voronezh, Russia
}

\begin{abstract}
The results of studies of alimentary correction of the efficiency of gas exchange in the lungs by the example of students and teachers of an engineering university with daily use of foods with known biocorrecting properties: $3.5 \mathrm{~g}$ of wheat germ oil (WGO), $50 \mathrm{~g}$ of wheat germ meal cake (WGMC), are presented $6.5 \mathrm{~g}$ of concentrated tissue fish oil (CTFO) and their combinations with the biomass of the consortium of lacto- and bifidobacteria $(10 \mathrm{~g})$. The efficiency of gas exchange processes was evaluated based on the analysis of the respiratory coefficient, the concentration of carbon dioxide $\left(\mathrm{CO}_{2}\right)$ and oxygen $\left(\mathrm{O}_{2}\right)$ in the exhaled gas mixture was determined using a TESTO-310 gas analyzer, an MDG-1201 capnograph, the values of which were recorded before and after daily use of the studied products during 30 days. The experimental group consisted of volunteers - teachers and university students aged 16 to 65 years, divided into 3 age groups: 16-24, 25-44 and 45-65 years old. It was established that the most effective antihypoxic drug is WGMC, in all age groups, the increase in average RR values amounted to 0.041 units, and $4.8 \%$ relative to the initial values. When using WGO, the change in RC was 0.032 , an increase compared to baseline $-3.7 \%$. In the $1 \mathrm{st}$, 2nd and 3rd age groups, the average change in RC was: $0,031,0,036$ and 0,043 units, relative to the initial indicators, the increase was 3.5, 4.2 and $5.0 \%$, respectively. It is proved that the combination of the studied biocorrector with the active forms of probiotic microorganisms provides a more active antihypoxic effect for all the studied products in all age groups. The effectiveness of the WGO was increased, the increase in RC was 0.049 units, for CTFO 0.024 units. The growth of RC relative to the initial values was 5.7 and $2.9 \%$, respectively. The synergism of the action of biocorrectors in combination with probiotics, by age groups amounted to $-0.035,0.033$ and 0.038 units, which is $4.1,3.8$ and $4.5 \%$ relative to the initial indicators.
\end{abstract}

\section{Introduction}

The ecology of the modern world, especially megacities, leads to an increase in the oxygen demand of our body, the deficiency of which is not covered during the day. Long stay in rooms with a large number of people, a sedentary lifestyle, high mental and nervous stress are significant factors that influence the manifestation of hypoxia that occurs in the body with inadequate supply of oxygen to tissues and organs or in violation of oxygen utilization. The pathological causes of hypoxia are various diseases of the broncho-pulmonary system, namely, chronic obstructive pulmonary disease, bronchial asthma, chronic heart failure, obesity, viral diseases, etc. One of the functions of breathing is gas exchange in the alveoli of the lungs, which ensures diffusion of molecular oxygen and carbon dioxide adequate metabolic demand for the concentration of these gases in arterial blood. An indicator of gas exchange efficiency is the respiratory coefficient (RC), calculated as the ratio of the amount of carbon dioxide $\left(\mathrm{CO}_{2}\right)$ extracted from the lungs to the oxygen $\left(\mathrm{O}_{2}\right)$ consumed over the same period of time, which shows which substances are predominantly oxidized [1,2]. During protein oxidation, $\mathrm{RC}$ is 0.81 , fat is 0.7 , carbohydrate is 1.0 , and with mixed nutrition, 0.82 .
During fasting, when the dissimilation of fats increases in the body, $\mathrm{RC}$ can fall to 0.6 and exceed 1.0 with intensive accumulation of fats in the body. Also, RC can exceed 1.0 with hyperventilation of the lungs, due to the additional removal of $\mathrm{CO}_{2}$ from the body in a bound state [3].

At the heart of all the vital processes of the body are energy transformations. The potential energy of organic compounds supplied with food passes into thermal, mechanical, electrical, chemical bond energy, which is then spent on plastic processes, performing muscle work, breathing, digestion, blood circulation, maintaining body temperature, overcoming osmotic forces during secretory and excretory processes, maintaining membrane potentials. In turn, the process of transforming food into energy depends on many physiological, biochemical and technological factors. Changing the composition of food systems through the introduction of biologically active compounds - biocorrections (vitamins, enzymes, antioxidants, eubiotics), it is possible to exert a biocorrective effect on the totality of metabolic processes, in particular gas exchange in the lungs, correct hypoxic states, and restore the equilibrium state of body systems [4]. 
As an alimentary biocorrector, biologically active additives were studied: Vitazar wheat germ oil (WGO), Vitazar wheat germ meal cake (WGMC), Eikonol cryoconcentrated tissue fish oil (CTFO), an activated consortium of lacto - and bifidobacteria "Biomatrix", having Streptococcus thermophilus, Casei subsp. Rhamnosus, L. acidophilus, L. plantarum, L. fermentum, B. bifidum, B. longum, B. Adolescentis in the concentration of active cells of at least $10^{9} \mathrm{CFU} / \mathrm{g}$ on a milk basis.

The bio-correcting properties of WGO are due to the high content of vitamins $\mathrm{A}, \mathrm{D}, \mathrm{E}$, polyunsaturated fatty acids, octocosanol and are confirmed by extensive clinical trials in the treatment of various diseases cardiovascular, gastroenterological, diabetes, hepatitis, infertility, burns and wounds, etc. [5, 6].

A by-product of the production of WGO is the protein-carbohydrate component of the embryo (cake) with a residual oil content of 6-8\% [7], registered as dietary supplement "Vitazar" flour [8-10]. The residual lipid fraction in flour from wheat germ cake (WGMC) is identical in composition to the pressed oil and hypothetically preserves its biological active properties $[11,12]$. In addition, WGMC contains up to $30 \%$ of a protein with a full amino acid composition, up to $30 \%$ of carbohydrates represented by pentosans, mono-, di-, oligo- and polysaccharides. Significant amounts in WGMC contain vitamins $\mathrm{B}_{1}, \mathrm{~B}_{2}, \mathrm{~B}_{6}, \mathrm{PP}, \mathrm{E}, \mathrm{K}$, macroand trace elements $-\mathrm{Zn}, \mathrm{Mn}, \mathrm{Mg}, \mathrm{Ca}, \mathrm{K}, \mathrm{Fe}, \mathrm{Se}, \mathrm{P}[13$, 14].

Cryoconcentrated tissue fish oil (CTFO) - dietary supplement "Eikonol" - a valuable active bioregulator of metabolic processes. It is obtained as a result of physicochemical effects on fish stock, which allows to destroy the cell membrane, followed by mechanical separation of the lipid fraction from the rest of the processed feed. CTFO is a source of $\omega-3$ PUFA - eicosapentaenoic and docosahexaenoic, vitamins A, D and E. Clinical studies conducted in a number of countries have clearly shown that lipids of marine organisms are an effective means of correcting lipid metabolism disorders in the human body, and prevent cardiovascular diseases systems, increased blood coagulation, etc. [15-17].

The bio-correcting properties of probiotic microorganisms include trophic and energy support of the macroorganism, energy supply of the epithelium, stimulation of the immune system, formation of immunoglobulins, regulation of intestinal motility, participation in the regulation, differentiation and regeneration of intestinal epithelium, cytoprotection, detoxification, elimination of endo- and exogenous toxic compounds mutagens, activation of drug compounds, formation of signaling molecules (neuro- and transmitters), maintenance of ionic, physical and chemical parameters of homeostasis of the epithelial zone, supply of substrates for lipo- and glucogenesis [1821].

The aim of the work is a comparative study of antihypoxic nutrients of plant (WGO, WGMC) and animal (CTFO) origin and their influence on the efficiency of gas exchange with the assessment of RC, on the example of students and teachers of the university, as well as identifying the role of the probiotic factor in increasing the antihypoxic properties of target biologically active substances

\section{Experimental}

The content of bioactive components in the studied WGO was: vitamin E - 180-200 mg/100 g, policosanol - 1.5$8.0 \mathrm{mg} / 100 \mathrm{~g}$, PUFA - $60 \mathrm{~g} / 100 \mathrm{~g}$, WGMC contained protein - 30-35 g/100 g, PUFA - 3-4 g/100 g, digestible carbohydrates - 45-47 g/100 g, dietary fiber - 18-26 $\mathrm{g} / 100 \mathrm{~g}$, vitamin $\mathrm{E}-25-30 \mathrm{mg} / 100 \mathrm{~g}$ (manufactured by Pulat LLC, RF); CTFO contained vitamins A - 6.60 $\mathrm{mg} / 100 \mathrm{~g}, \mathrm{D}-100 \mathrm{mcg} / 100 \mathrm{~g}, \mathrm{E}-100 \mathrm{mg} / 100 \mathrm{~g}$, PUFA - at least $25 \mathrm{~g} / 100 \mathrm{~g}$ (manufactured by LLC NPP Trinita, $\mathrm{RF}$ ); the biomass of the consortium of lacto- and bifidobacteria "Biomatrix" (Streptococcus thermophilus, Casei subsp. Rhamnosus, L. acidophilus, L. plantarum, L. fermentum, B. bifidum, B. longum, B. adolescentis) was characterized by a concentration of active cells of at least $10^{9} \mathrm{CFU} / \mathrm{ml}$, titratable acidity was $80-100^{\circ} \mathrm{T}, \mathrm{pH} 4.61-$ 4.65 (production of FSBEI HE VGUIT, Russian Federation). Biomass growth was carried out on skim milk in the temperature range $37-42{ }^{\circ} \mathrm{C}$ to a $\mathrm{pH}$ of $4.4-4.7$, the standard fermentation time was 12-14 hours.

The respiratory coefficient (RC) was calculated as the ratio of the concentrations of carbon dioxide $\left(\mathrm{CO}_{2}\right)$ released from the body in the exhaled gas-air mixture to oxygen $\left(\mathrm{O}_{2}\right)$ absorbed at the same time.

To study the concentration of $\mathrm{O}_{2}$ and $\mathrm{CO}_{2}$ in the exhaled gas mixture, a TESTO-310 gas analyzer Testo Rus LLC was used, the sensitivity of the device for $\mathrm{O}_{2}$ was: concentration range $0-21 \%$ vol, resolution $0.01 \%$ vol, error $\pm 0.2 \%$ vol. $\mathrm{CO}_{2}$ concentration range: 0 - $100 \%$ vol, resolution $0.01 \%$ vol, error $\pm 0.2 \%$ vol., as well as a capnograph MDG-1201, the range of measuring $\mathrm{CO}_{2}$ concentration was $0-13 \%$ vol, error $\pm 0.3 \%$ Forced ventilation and air conditioning were absent in the room (laboratory lecture hall), the room was not ventilated, factors that significantly affect the initial oxygen content in the room were minimized. The concentration of $\mathrm{O}_{2}$ and $\mathrm{CO}_{2}$ in the exhaled gas mixture was determined immediately after 90 minutes of classroom lecture classes, during which the motor activity of all students and teachers was the same and minimal. Before conducting experimental studies, the patient was at rest for 10 minutes. To obtain stable and more significant results in terms of $\mathrm{CO}_{2}$ content, air intake into the lungs was accompanied by an exhalation delay of at least 15$20 \mathrm{sec}$ until constant values of $\mathrm{O}_{2}$ and $\mathrm{CO}_{2}$ concentration were established on the instrument display [22, 23].

The determination of each of the studied indicators was carried out in triplicate for all students and teachers examined, with the subsequent obtaining of arithmetic mean values $[22,23]$.

The reliability of the obtained arithmetic mean values of the studied parameters was evaluated using the nonparametric statistics criterion of Mann-Whitney [24].

In the research process, volunteer patients were divided into four groups. The first group was given $3.5 \mathrm{~g}$ of WGO, the second group consumed WGMC in an amount ensuring the supply of $3.5 \mathrm{~g}$ of oil, which corresponded to $50 \mathrm{~g}$ of cake, in the form of a culinary product [13]. The third and fourth groups used a probiotic emulsion containing $3.5 \mathrm{~g}$ of WGO or $6.5 \mathrm{~g}$ of CTFO in 
combination with $10 \mathrm{~g}$ of biomass of lactobacilli and bifidobacteria. The stability of emulsions was at least 70$75 \%$, due to the high exopolysaccharide activity of probiotic biomass [25]. These food forms were used by volunteers regardless of meals, without correction of the main diet. The duration of the experimental studies was 30 days, at the beginning of reception and at the end of taking biocorrectors, the studied parameters were controlled. On the day of sampling, the studied biocorrector were not given out to the subjects, the time interval between the use of the studied products and the sampling was at least 24 hours.

The four experimental groups of patients voluntarily included men and women aged 16 to 65 years old students and teachers of the Voronezh State University of Engineering Technologies, spending at least 6 hours daily under the same conditions - university premises. All subjects had not previously used the studied biocorrectors.

The number of experimental groups was 70, 36, 58, and 51 people, respectively, the number of control groups that did not consume the studied products was similar (Table 1) [22, 23].

\section{Results and discussion}

Assessment of the respiratory coefficient values in all age groups showed that the most effective antihypoxic drug is WGMC, the increase in the average $\mathrm{RC}$ values for all age groups amounted to 0.041 units. When taking WGO, the level of RC increased by 0.032 units, also, on average, for all age groups (Fig. 1).

When comparing the results with the age of the patients, it was found that in the 1st, 2nd and 3rd age groups, the increase in $\mathrm{RC}$ was $0.031,0.036$ and 0.043 , respectively (Fig. 2).

In accordance with the calculated values of the MannWhitney criterion, it was found that the revealed differences in the arithmetic mean values of the studied parameters are reliable (Table 2).

Based on the analysis of the results of experimental studies, it was found that the studied biocorrector WGO and WGMC can be attributed to nutritional factors of biocorrective action, providing increased efficiency of lung gas exchange in age groups from 18 to 65 years. By the example of the studied biocorrectors containing the same amount of the target biologically active substance the lipid fraction of wheat germ, the possibility of a fundamentally new integrated approach in assessing the biological activity of food objects of various nature is proved. Higher efficiency of WGMC is due to the significant content in its composition of a spectrum of potentially useful nutrients - mineral elements, watersoluble vitamins, prebiotics, and proteins.

The next stage of experimental studies was the confirmation of the hypothesis about the possibility of increasing the effectiveness of the target biologically active substances (BAS) by combining them with probiotic microorganisms and the comparative assessment of the biocorrective effect of probiotic emulsions with WGO and WGMC [15-17].

It was found that the combination of the studied biocorrectors with probiotic microorganisms is specific for each studied biocorrector (Fig. 3). For a probiotic emulsion with CTFO, a less pronounced effect on the increase in RC was revealed in comparison with an emulsion containing WGO. When taking a probiotic emulsion with WGO and CTFO, RC increased by 0.049 and 0.024 units, respectively.

Table 1. Number Of Experimental Groups

\begin{tabular}{|c|c|c|c|c|}
\hline \multirow{2}{*}{$\begin{array}{c}\text { Name of } \\
\text { biocorrector }\end{array}$} & \multicolumn{3}{|c|}{ Age of patients, years } & \multirow{2}{*}{ Total } \\
\cline { 2 - 4 } & $\mathbf{1 6 - 2 4}$ & $\mathbf{2 5 - 4 4}$ & $\mathbf{4 5 - 6 5}$ & \\
\hline WGO & 35 & 18 & 17 & 70 \\
\hline WGMC & 24 & 5 & 7 & 36 \\
\hline $\begin{array}{c}\text { Probiotic } \\
\text { emulsion with the } \\
\text { inclusion of WGO }\end{array}$ & 28 & 20 & 10 & 58 \\
\hline $\begin{array}{c}\text { Probiotic } \\
\text { emulsion with the } \\
\text { inclusion of } \\
\text { WGMC }\end{array}$ & 21 & 20 & 10 & 51 \\
\hline
\end{tabular}

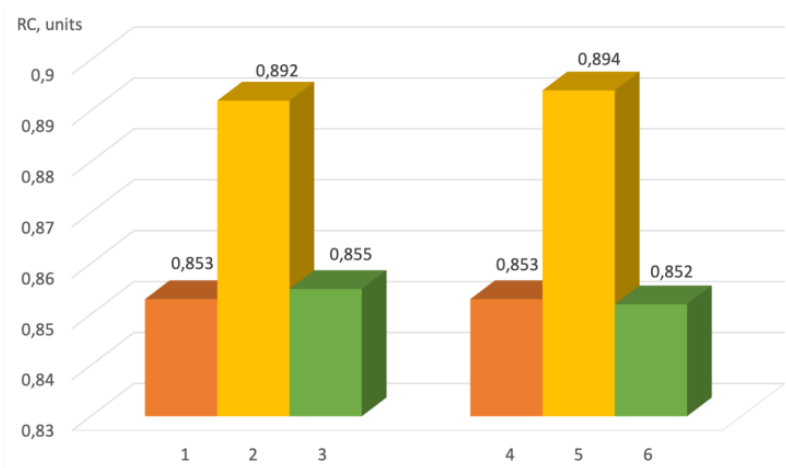

Fig. 1. The average numerical values of $\mathrm{RC}$ for the studied age groups: 1 (4) - before receiving WGO (WGMC); 2 (5) - after 30 days of receiving WGO (WGMC); 3 (6) - control group (throughout the period)

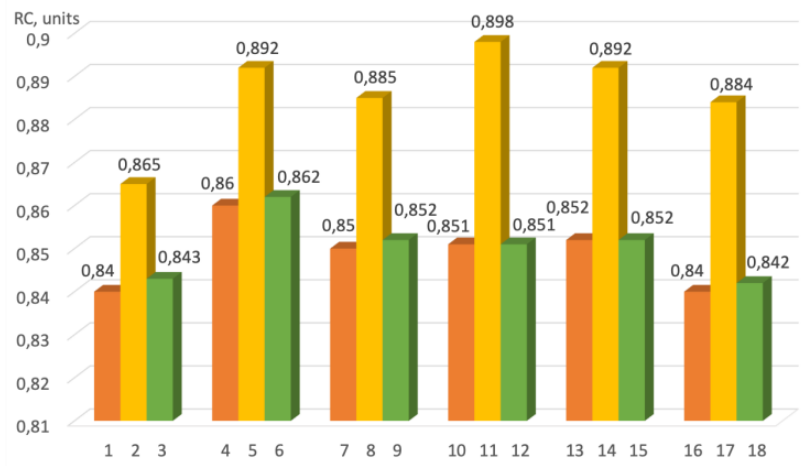

Fig. 2. RC values in the studied age groups: $1,4,7(10,13,16)$ - before receiving WGO (WGMC) in the 1st, 2nd and 3rd age groups; 2, 5, $8(11,14,17)$ - after 30 days of receiving WGO (WGMC) in the 1st, 2nd and 3rd age groups; 3, 6, 9 (12, 15, 18) - control group (throughout the entire period)

As a result of experimental studies, a correlation was established between the age of patients and the achieved antihypoxic effect from taking the probiotic forms under consideration, so in the 1st, 2nd and 3rd age groups, an increase in RC by $0.035,0.033$ and 0.038 units was revealed, respectively (Fig. 4). The results of experimental studies on the reception of probiotic emulsions with WGO allow us to state a more pronounced increase in the level of RC by 0.017 units, in comparison with the effect of taking WGO.

The reliability of the data is confirmed by the values of the Mann-Whitney criterion (Table. 3). 
Table 2. The calculated values of the Mann-Whitney criterion

\begin{tabular}{|c|c|}
\hline $\begin{array}{c}\text { After the course of taking } \\
\text { WGO }\end{array}$ & $\begin{array}{c}\text { After the course of taking } \\
\text { WGMC }\end{array}$ \\
\hline \multicolumn{2}{|c|}{ I group, $\mathrm{U}_{\mathrm{Kp}}=113.0(30.0)$} \\
\hline 97.5 & 23.5 \\
\hline \multicolumn{2}{|c|}{ II group, $\mathrm{U}_{\mathrm{kp}}=99.0(5.0)$} \\
\hline 73.5 & 4.0 \\
\hline \multicolumn{2}{|c|}{ III group, $\mathrm{U}_{\mathrm{Kp}}=87.0(8.0)$} \\
\hline 68.0 & 3.5 \\
\hline
\end{tabular}

The experimentally established positive effects of receiving WGO, WGMC and CTFO for the correction of pulmonary gas exchange correlate with biomedical indications of their use in the treatment of various diseases [4-7, 15-18, 23].

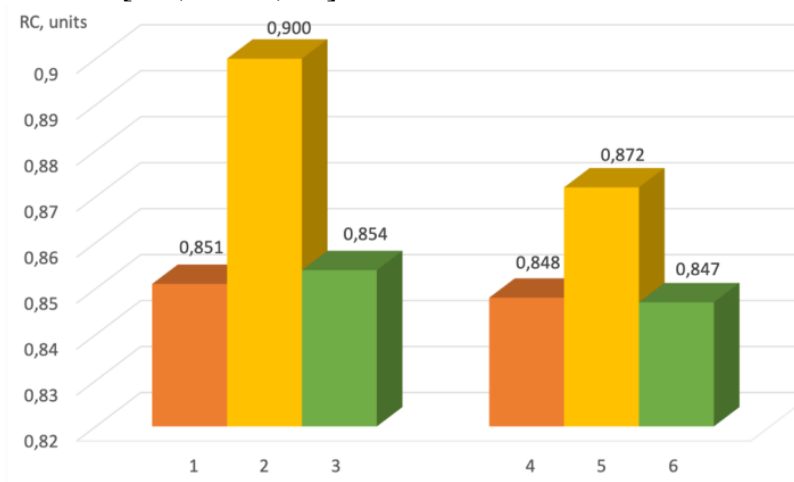

Fig. 3. Average numerical values of $\mathrm{RC}$ for the studied age groups: 1 (4) - before receiving WGO (WGMC); 2 (5) - after 30 days of receiving WGO (WGMC); 3 (6) - control group (throughout the period)

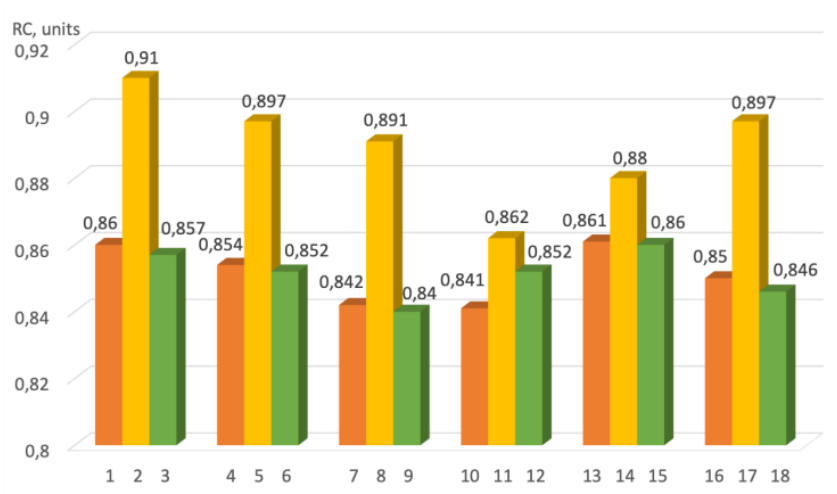

Fig. 4. RC values in the studied age groups:

$1,4,7(10,13,16)$ - before receiving WGO (WGMC) in the 1st, 2nd and 3rd age groups; 2, 5, $8(11,14,17)$ - after 30 days of receiving WGO (WGMC) in the 1st, 2nd and 3rd age groups; $3,6,9(12,15,18)$ - control group (throughout the entire period)

Table 3. The calculated values of the Mann-Whitney criterion

\begin{tabular}{|c|c|}
\hline $\begin{array}{c}\text { After a course of taking a } \\
\text { probiotic emulsion with } \\
\text { the inclusion of WGO }\end{array}$ & $\begin{array}{c}\text { After a course of taking a } \\
\text { probiotic emulsion with } \\
\text { the inclusion of CTFO }\end{array}$ \\
\hline \multicolumn{2}{|c|}{ I group, $\mathrm{U}_{\mathrm{kp}}=23.0(23.0)$} \\
\hline 16.5 & 16.0 \\
\hline \multicolumn{2}{|c|}{ II group, $\mathrm{U}_{\mathrm{kp}}=23.0(23.0)$} \\
\hline 15.0 & 18.0 \\
\hline \multicolumn{2}{|c|}{ III group, $\mathrm{U}_{\mathrm{Kp}}=23.0(23.0)$} \\
\hline 17.0 & 17.5 \\
\hline
\end{tabular}

\section{Conclusion}

Based on the analysis of the results of experimental studies, it was found that the most effective antihypoxic drug is WGMC (an increase in the average RC values by 0.041 units was revealed, which is $4.8 \%$ relative to the initial values). Less pronounced changes in the studied parameters were recorded when taking $\mathrm{WGO}$, an increase in the level of RC was recorded by 0.032 units, an increase relative to the baseline was $3.7 \%$. When comparing the results with the age of the patients, it was found that in the 1st, 2nd and 3rd age groups, the average change in $\mathrm{RC}$ was $0.031,0.036$, and 0.043 units; relative to the initial indicators, the growth was $3.5,4.2$, and $5.0 \%$, respectively.

An analysis of the data showed that the combination of the use of the studied biocorrectors with probiotic microorganisms in active form provides a more significant antihypoxic effect in all age groups. An increase in the level of RC by $0.035,0.033$ and 0.038 units was revealed in the $1 \mathrm{st}, 2 \mathrm{nd}$ and $3 \mathrm{rd}$ age groups, respectively, which was $4.1,3.8$ and $4.5 \%$ relative to the initial indicators. The established effects are specific for each biocorrector under study - for WGO 0.049 units, for CTFO - 0.024 units, the increase in RC relative to the initial values was 5.7 and $2.9 \%$, respectively. The revealed results of experimental studies convincingly prove the role of nutritional biocorrectors in increasing the efficiency of gas exchange in the lungs, regardless of gender and age, which is especially relevant for people suffering from pulmonary diseases, as well as to improve the performance of people in closed rooms with low mobility and mental stress.

\section{References}

1. S.V. Pogodina and G.D. Aleksanyants, Physiological culture, sport - science and practice, 1, 53-58 (2019)

2. A.V. Shepilov and A.V. Nenasheva, Vestnik SUSU, 61-65 (2012)

3. S.B. Noreiko, E.S. Popov, M.Y. Syromyatnikov, and E.A. Artemova, Biomedical problems of physical education and sport, 12, 61-63 (2011)

4. N.S. Rodionova, Alimentary factors for the correction of nutritional status and physiological conditions in the $1 \mathrm{st}$ International Symposium Innovations in Life Sciences (ISILS 2019) October, 2019, Belgorod, Russia (2019)

5. L.A. Shpagina, Methodical guide for doctors "The use of wheat germ oil and flour" Vitazar " in the clinic of internal diseases (Novosibirsk State Medical, Academy Novosibirsk, 2007)

6. L.A. Shpagina, Novosibirsk State Medical Academy, 2, 44-48 (2008)

7. A.B. Vishnyakov and V.N. Vlasov, The germ of health ( Kolos, Moscow, 2011)

8. N.S. Rodionova, E.S. Popov, V.Yu. Kustov, A.A. Rodionov, and N.A. Rodionova, International Journal of Civil Engineering and Technology, 10, 01, 17181730 (2019)

9. N.S. Rodionova, E.S. Popov, and O.A. Sokolova, Nutrient correctors of nutritional status based on products of deep processing of low-oil raw materials: monograph" (Voronezh State University of Engineering Technologies, Voronezh, 2016)

10. N.S. Rodionova, K.K. Polyansky, E.S. Popov, and N.A. Rodionova, Dairy industry, 12, 28-30 (2019) 
11. A.B. Vishnyakov, V.N. Vlasov, N.S Rodionova T.V. Alekseeva, E.S. Popov, and A.A. Dyakov, The germ of health: monograph (Voronezh State University of Engineering Technologies,Voronezh , 2018).

12. N.S. Rodionova and T.V. Alekseeva, Food technology of a balanced PUFA composition (Voronezh State University of Engineering Technologies, Voronezh, 2015)

13. E.S. Popov, N.S. Rodionova, O.A. Sokolova, and N.Y. Mazurenko, Hygiene and sanitation, 95, 1, 7984 (2016)

14. N.S., Rodionova T.V. Alekseeva, E.S. Popov, Y.O. Kalgina, and A.A. Natarova, Hygiene and sanitation, 95, 1, 74-79 (2016)

15. V.A. Isaev and S.V. Simonenko, Nutrition issues, 85 , 5, 120-127 (2016)

16. V.A. Isaev, Food industry, 1, 30-31 (2015)

17. Isaev V.A. Human Physiology, 26, 99-104 (2000)

18. M.M. Eamonn, Clinical Gastroenterology and Hepatology, 17, 2, 333-344 (2019)

19. R.G. Kerry, Journal of Food and Drug Analysis, 26, 3, 927-939 (2018)
20. Eric Banan-Mwine, Food Science and Human Wellness, 4, 2, 56-65 (2015)

21. L.R. Valdovinos-García, Revista de Gastroenterología de México, 1-7 (2018)

22. I.E. Esaulenko, N.S. Rodionova, E.S. Popov, E.P. Melikhova, and R.D. Hatuaev, Hygiene and sanitation, 94, 9, 42-46 (2015)

23. A.B. Vishnyakov, N.S. Rodionova, A.V. Isaev, E.S. Popov, E.V. Belokurova, N.A. Rodionova, and E.A. Interesova, Nutrition. Energy. Entropy: Monograph, (Voronezh State University of Engineering Technologies, Voronezh, 2020)

24. Y.P. Grachev and Y.M. Plaksin, Mathematical methods of experiments planning (DeLiPrint, Moscow, 2005)

25. N.S. Rodionova, E.S. Popov, and N.A. Rodionova, Actual biotechnology, 3, 313 (2019) 